\title{
CORRESPONDENCE
}

\section{Semantics or pedantry?}

To the Editors:

Naturally in your positions, you are interested in the use of words, as should be your authors and must be your readers. Here are three examples.

\section{SIGNIFICANT}

This has been with us for decades. It is sometimes accompanied by statistical probability values in parentheses. It literally means "full of meaning or import" [1]. Used alone it means the authors are stressing, but not justifying, the scientific importance of their results. Even if significant, the results are often unimportant, uninteresting and unconvincing. Unfortunately the word will be with us for many more decades.

\section{ROBUST}

Frequent use of the word started a decade or so ago, but its use now seems, thankfully, to be in decline. Its users seem to mean that their results and conclusions are beyond argument and must be accepted, since they are even more than significant. It literally means "strong, vigorous, healthy" [1]. Some scientific statements claimed to be robust are like a house of cards.

\section{PARADIGM}

This is recently becoming more popular. I have encountered it 15 times in a few recent publications related to my own research interest (cough). The authors usually seem to mean that their results open a new and important understanding into a hitherto perplexing problem. It literally means "a pattern or example" [1]. But it is also claimed to be "a buzzword deployed by dumb people wishing to sound important" [2]. No less an authority than Mervyn King (Governor of the Bank of England, and possibly a scientist manqué) said: "Paradigm is a word too often used by those who would like to have a new idea but cannot think of one" [2].

Of course the use of "paradigm" is significant, but I hope the word is not so robust that its use in scientific literature survives the present decade.

To complete the analysis, Pubmed [3] gives 1,696,440 references to "significant", 55,783 to "robust" and 47,082 to "paradigm". This correspondence contains some paradigms, and it may require a robust but not very significant updating of these numbers.

\section{J. Widdicombe \\ University of London, London, UK.}

Correspondence: J. Widdicombe, University of London, London, UK. E-mail: johnwiddicombej@aol.com

Statement of Interest: None declared.

\section{REFERENCES}

1 Oxford English Dictionary. 2nd Edn. Oxford, Oxford University Press, 1989.

2 Bates S. Diary: Pickles's way? Axe a quango, get a Jag. Guardian; August 202010.

3 PubMed. www.ncbi.nlm.nih.gov/pubmed/ Date last accessed August 28, 2010.

DOI: $10.1183 / 09031936.00138510$

\section{The BODE index as a tool to predict survival in COPD lung transplant candidates}

\section{To the Editors:}

LAHZAMI et al. [1] state that lung transplantation conferred a significant survival benefit in their cohort of patients undergoing the procedure for chronic obstructive pulmonary disease (COPD). They came to this conclusion by comparing observed posttransplant survival with predicted survival derived from the body mass index, airflow obstruction, dyspnoea and exercise capacity (BODE) index. They also suggest that the benefit was possibly underestimated due to a limited follow-up time.

Unfortunately, the authors do not discuss an important limitation. The BODE index, as described by CeLLI et al. [2], was assessed in a population that differed in at least two important characteristics from the transplanted cohort of LAHZAMI et al. [1]. The first is the mean age (55 yrs for transplanted subjects versus $>65$ yrs in the original paper by CELLI et al. [2]). The second is the smoking status, as current smokers are denied lung transplantation, but current smoking was not an exclusion criterion for the study by CELLI et al. [2].

Since age [3, 4] and smoking status [5] are two important factors predicting survival in COPD patients, it is hazardous to use the BODE index to compare observed and predicted mortality, as the authors did, since there is a potential for an underestimation of the predicted survival derived from the BODE index in this particular subset of COPD patients. 
This obviously does not prevent the BODE index from being useful in the assessment of COPD candidates for lung transplantation.

\section{E. Marchand}

Service de Pneumologie, Université Catholique de Louvain, Cliniques Universitaires UCL de Mont-Godinne, Yvoir, Belgium.

Correspondence: E. Marchand, Service de Pneumologie, Université Catholique de Louvain, Cliniques Universitaires UCL de Mont-Godinne, 5530 Yvoir, Belgium. E-mail: eric. marchand@uclouvain.be

Statement of Interest: None declared.

\section{REFERENCES}

1 Lahzami S, Bridevaux PO, Soccal PM, et al. Survival impact of lung transplantation for COPD. Eur Respir J 2010; 36: 74-80.

2 Celli BR, Cote CG, Marin JM, et al. The body-mass index, airflow obstruction, dyspnea, and exercise capacity index in chronic obstructive pulmonary disease. N Engl J Med 2004; 350: 1005-1012.

3 Anthonisen NR, Wright EC, Hodgkin JE. Prognosis in chronic obstructive pulmonary disease. Am Rev Respir Dis 1986; 133: 14-20.

4 Puhan MA, Garcia-Aymerich J, Frey M, et al. Expansion of the prognostic assessment of patients with chronic obstructive pulmonary disease: the updated BODE index and the ADO index. Lancet 2009; 374: 704-711

5 Hersh CP, DeMeo DL, Al Ansari E, et al. Predictors of survival in severe, early onset COPD. Chest 2004; 126: 1443-1451.

DOI: $10.1183 / 09031936.00117610$

\section{From the authors:}

We thank E. Marchand for his interest and comments regarding our manuscript. We agree that our cohort of severe chronic obstructive pulmonary disease (COPD) patients undergoing lung transplantation [1] differed from the original BODE (body mass index, airflow obstruction, dyspnoea and exercise capacity) index validation cohort [2] by being of a younger age and by the absence of current smokers. This may have led, as suggested, to an underestimation of our cohort's predicted survival.

However, pulmonary hypertension $[3,4]$ and hypercapnia [5, 6] are other COPD prognostic factors that may have differentiated our cohort from the BODE index validation cohort. Indeed, as both are longstanding criteria for lung transplant listing in COPD patients [7], it is likely that patients with hypercapnia and pulmonary hypertension were over-represented in our cohort when compared to patients with similar BODE index scores in the BODE index validation cohort. In contrast to the differences in age and current smoking status, this may have led to an overestimation of our cohort's predicted survival.

As acknowledged in our article, the BODE index has not been specifically validated in a COPD population listed for transplantation. The $95 \%$ confidence interval of predicted survival was therefore used in our analysis. We believe that this allowed to account for most of the comorbidity differences between our cohort and the BODE index validation cohort.

The Lung Allocation Score (LAS), implemented in the USA since 2005, would theoretically be a more transplantationspecific predictor of survival. However, in contrast to the BODE index, it has not been prospectively validated. The survival probability while on waiting list and $1 \mathrm{yr}$ after transplantation were both used to design the LAS. As such, it cannot be used to determine the effect of lung transplantation on survival. Furthermore, although an association with the probability of dying while on a waiting list has been demonstrated [8], the LAS has not been validated as a predictor of the duration of survival. The BODE index may not be the perfect tool to predict mortality in a COPD population listed for transplantation. Nevertheless, it is probably the best currently available one.

\section{S. Lahzami and J-D. Aubert}

Service de Pneumologie, Centre Hospitalier Universitaire Vaudois, Lausanne, Switzerland.

Correspondence: S. Lahzami, Service de Pneumologie, Centre Hospitalier Universitaire Vaudois, Rue du Bugnon 36, 1011 Lausanne, Switzerland. E-mail: Samir.Lahzami@chuv.ch

Statement of Interest: A statement of interest for J-D. Aubert can be found at www.erj.ersjournals.com/site/misc/statements. xhtml

\section{REFERENCES}

1 Lahzami S, Bridevaux PO, Soccal PM, et al. Survival impact of lung transplantation for COPD. Eur Respir J 2010; 36: 74-80.

2 Celli BR, Cote CG, Marin JM, et al. The body-mass-index, airflow obstruction, dyspnea, and exercise capacity index in chronic obstructive pulmonary disease. N Engl J Med 2004; 350: 1005-1012.

3 Incalzi RA, Fuso L, De Rosa M, et al. Electrocardiographic signs of chronic cor pulmonale: a negative prognostic finding in chronic obstructive pulmonary disease. Circulation 1999; 99: 1600-1605.

4 Oswald-Mammosser M, Weitzenblum E, Quoix E, et al. Prognostic factors in COPD patients receiving long-term oxygen therapy: importance of pulmonary artery pressure. Chest 1995; 107: 1193-1198.

5 Kanner RE, Renzetti AD Jr, Stanish WM, et al. Predictors of survival in subjects with chronic airflow limitation. Am J Med 1983; 74: 249-255.

6 Foucher P, Baudoin N, Merati M, et al. Relative survival analysis of 252 patients with COPD receiving long-term oxygen therapy. Chest 1998; 113: 1580-1587.

7 International guidelines for the selection of lung transplant candidates. The American Society for Transplant Physicians (ASTP)/American Thoracic Society (ATS)/European Respiratory Society (ERS)/International Society for Heart and Lung Transplantation (ISHLT). Am J Respir Crit Care Med 1998; 158: 335-339.

8 Nunley DR, Bauldoff GS, Holloman CH, et al. The Lung Allocation Score and survival in lung transplant candidates with chronic obstructive pulmonary disease. Lung 2009; 187: 383-387.

DOI: $10.1183 / 09031936.00129810$ 